\title{
ANTROPOLOGÍA DEL SUFRIMIENTO SOCIAL
}

\author{
Fina ANTÓN HURTADO \\ Universidad de Murcia \\ fmanton@um.es
}

\begin{abstract}
ANTHROPOLOGY OF SOCIAL SUFFERING
Resumen: El sufrimiento social no está causado exclusivamente por el dolor físico y su repercusión emocional, más bien se refiere a una expresión de la condición humana más extraordinaria, que es la base de la evolución cultural, y que consiste en que en los seres humanos, no hay acción sin intención, y esa intencionalidad se fundamenta en el conjunto de creencias, valores y normas que se forjan a través de la cultura, por tanto, el sufrimiento social se produce cuando hay un choque entre las creencias y los valores de la sociedad y las de las personas o la imposibilidad de aplicarlas. En este caso, es la tensión de la adaptación cultural la que induce la aparición de enfermedades, tanto físicas (enfermedades laborales), como psicológicas (depresión, estrés, ansiedad, etc.) tan frecuentes en las sociedades complejas y que responden a la carencia de sentido. La globalización económica coloniza no solo culturas sino, y sobre todo, los cuerpos y las mentes de las personas. La realidad virtual nos sitúa ante un espejismo de felicidad inexistente. Asistimos a un salto cognitivo-emotivo sin precedentes, cuya selección de las emociones que comunicamos a los demás, invisibiliza las que no son socialmente valoradas, pero no nos salva de sufrirlas. El individualismo imperante en las sociedades occidentales, encapsula el sufrimiento agravándolo y patologizando su gestión cultural. En esta contribución pretendo esbozar la presencia del sufrimiento social a lo largo del ciclo vital, a través de la mirada antropológica, rescatando, no sólo las palabras, sino también, los gestos, los sonidos y las emociones de nuestros informantes.
\end{abstract}

Abstract: Social suffering is not caused exclusively by physical pain and its emotional repercussion, rather it refers to an expression of the most extraordinary human condition, which is the basis of cultural evolution, and which consists in the fact that in the humans there is not action without intention. This intentionality is based on the set of beliefs, values and norms that are forged through culture. Therefore, social suffering occurs when there is a clash between the beliefs and values of society and those of the persons, or the impossibility of applying them. In this case, it is the tension of cultural adaptation that induces the appearance of diseases, both physical (occupational diseases) and psychological (depression, stress, anxiety, etc.), so frequent in complex societies that they respond to the lack of meaning. Economic globalization colonizes not only cultures but, above all, the bodies and minds of people. Virtual reality places us before a mirage of happiness that does not exist. We are witnessing an unprecedented cognitive-emotional leap, whose selection of the emotions that we communicate to others, make invisible those who are not socially valued, but does not save us from suffering them. Individualism prevailing in Western societies encapsulates suffering by aggravating it and pathologizing its cultural management. Through an anthropological view, this paper wants to outline the presence of social suffering throughout the life cycle, and to rescue not only the words but also the gestures, sounds and emotions of our informants.

Palabras clave: Antropología. Emoción. Sufrimiento Social. Sentido. Ciclo Vital Anthropology. Emotion. Social Suffering. Meaning. Life Cycle 


\section{Introducción}

La rapidez con la que la realidad virtual está colonizando nuestras vidas, nos sitúa ante un espejismo de felicidad inexistente. Si observamos las imágenes que aparecen en las redes sociales son mayoritariamente de momentos de felicidad que compartimos con los demás, ocultando los momentos de tristeza y sufrimiento que invisibilizamos. Podemos acceder sin dificultad a toda una serie de videos versionados en los que los protagonistas sufren, pero se ridiculiza ese sufrimiento con comentarios "jocosos" para arrancar la carcajada fácil de los espectadores y por ende a la insensibilización de los mismos ante el padecimiento ajeno.

Que el desarrollo de las tecnologías de la información y la comunicación han reforzado el sistema neoliberal, no parece discutible, de ahí que la célebre canción de Bobby McFerrin "Don'tWorry, Be Happy" se ha convertido en el life motive de este sistema económico, generando expectativas positivas en entornos dolorosos, o como dice Pérez (2012), promueve un optimismo sin escrúpulos para transformar las respuestas a un mundo en crisis, en las que cabría dar en un mundo ideal.

La sociabilidad que era inherente al proceso de humanización, como decía Aristóteles cuando definía al hombre como zoon politikón, se llevaba a cabo en la polis, la ciudad, en la comunidad en la que las personas se relacionan físicamente y se integran en un entorno real, pero ésta se está sustituyendo rápidamente por la "comunidad virtual" suspendida en la "nube" y sin localización concreta. Asistimos a un salto cognitivo-emotivo sin precedentes, cuya selección de las emociones que comunicamos a los demás, invisibiliza las emociones que no son socialmente valoradas, pero no nos salva de sufrirlas. El individualismo imperante en las sociedades occidentales, encapsula el sufrimiento agrabándolo y patologizando su gestión cultural, porque en las sociedades laicas, se han extirpado los significados religiosos para injertar expectativas biotecnológicas que anulen el dolor y el sufrimiento.

Coincido con Lisón Tolosana (2005), en reivindicar la Antropología Social como la ciencia que estudia el sentido y el significado de la vida, de su fragilidad o de la muerte, estableciendo una visión unitaria, antropológicamente hablando, para recuperar la epistemología en primera persona, rescatando, no sólo las palabras, sino también, los gestos, los sonidos y las emociones de nuestros informantes. En este sentido pretendo esbozar en esta contribución la presencia del sufrimiento a lo largo del ciclo vital, analizando previamente la necesidad de reflexionar sobre el sufrimiento social.

\section{El sufrimiento como emoción.}

La antropología social se ha interesado en dilucidar cómo nuestra especie ha imbricado naturaleza y cultura y a través de las emociones comprobamos que tienen una base neurofisiológica (Damasio: 2011) pero de ninguna manera la han cosificado para prescindir de la dimensión sociocultural en la que el universo emocional se constituye y adquiere sentido para el sujeto (Ramírez Goicoechea: 2001: 181). Las emociones son la matriz sobre la que se mueve la vida social, son tipos básicos de conductas relacionales sobre las que se da la comunicación necesaria para crear los diversos mundos culturales (Fericgla: 2012: 2). "El hombre está afectivamente en el mundo y la existencia es un hilo continuo de sentimientos más o menos vivos o difusos, cambiantes, que se contradicen con el correr del tiempo y las circunstancias" (Le Breton, 1999: 103). Su estudio debe plantearse desde una perspectiva ecosistémica, es decir, de la relación persona-medio. En este enfoque la tensión que se establece entre el sujeto y su medio físico y sociocultural constituye la base fundante de la emoción. Su modo de estar y ser en este medio crea un circuito completo o campo de acción, configurado por una tensión creadora o tono personal, desde la que interpreta y valora su situación real y sus posibilidades de acción. La interacción entre persona y medio ha sido denominada el circuito de la mismidad (Álvarez Munárriz, 1997: 400; Milton, 2005: 197). 
A esa tensión o tono es a lo que llamamos sentimiento o emoción. Los sentimientos son las manifestaciones de la gestión cultural de las emociones, la razón es en muchas ocasiones emocional, la "razón sensible" en palabras de Maffesoli (1997), y no se trata de una actividad puramente mental sino global pues implica a todo el cuerpo del sujeto en acción (Fericgla, 2012; De Pina-Cabral, 2003: 98; Mairal Buil, 2003: 136; Antón Hurtado, 2015: 263)

Charles Darwin en su libro La expresión de la emociones en los animales y en el hombre, publicado en 1872, desvela la función evolutiva de las emociones a través de su capacidad para propiciar la comunicación social, especialmente a la hora de la selección de la pareja, lo que supone garantizar la supervivencia de la especie. Darwin propone seis componentes universales que articulan las emociones, tomando como emociones principales, la alegría, que estimula la aproximación (con su manifestación cultural según la intensidad y el contexto, que va desde el éxtasis a la serenidad), y el miedo, que supone la evitación (recorrida desde el pavor al temor). Entre ambas emociones fundamentales, sitúa la sorpresa (que va del asombro a la distracción), el asco (de la aversión al aburrimiento), la tristeza (de la desolación a la melancolía), y la ira (de la furia al fastidio). Estas emociones básicas son combinables y así podremos tener el sobrecogimiento como resultado de la mezcla de miedo y sorpresa, la sumisión como la unión de miedo y confianza, el amor como expresión de confianza y dicha.

Las emociones, en tanto que propiciadoras de la comunicación social constituyen la red sobre la que se conforma la vida social, porque, como constató Darwin, los seres humanos, en tanto que animales sociales, necesitamos comunicar nuestro estado emocional a los demás, lo que llevamos a cabo, inicialmente, a través de la expresión facial. Tras la lectura de esta obra, Freud amplia la funcionalidad de las emociones y considera que influyen en la capacidad de actuación racional de los seres humanos, hasta tal punto, que la conciencia había evolucionado porque los organismos dotados de ella podían "sentir" las emociones y lejos de entorpecer nuestras decisiones, las favorecen y nos ayudan a evitar el peligro y a aproximarnos a posibles fuentes de placer. Para Levinas (1993b) el rostro y especialmente la mirada es el principio de la conciencia emotiva, y la identidad sólo puede construirse a partir de la mirada del otro. La vigencia de esta afirmación es constatable en la crisis de identidad que sufren muchos usuarios de las nuevas formas de comunicación virtual, que condensan la interacción con otros cibernautas en la escritura sin poder apreciar la mirada del otro. Dado que todos los rostros humanos tienen los mismos órganos, dos ojos, una nariz y una boca, los aspectos sensoriales y motores de la comunicación de las emociones son universales, son una expresión de la naturaleza que confirma la unidad de la especie:

"Hoy hay pruebas de que distintas culturas han añadido matices a estas expresiones comunes que los foráneos deben aprender a reconocer para entender plenamente las emociones expresadas" (Kandel, 2013: 359).

De lo que podemos deducir que en la expresión de las emociones también influye el proceso de socialización en el que estamos inmersos los seres humanos y que tiene como resultado la variedad de sentimientos derivados de esas emociones, cuya expresión depende de la cultura en la que se manifieste. Esta actividad relacional que se observa en la mente humana nos obliga a considerar a la persona como "un agente creativo dentro de un campo total de relaciones cuyas transformaciones describen un proceso evolutivo" (Ingold, 1991; cf. Maturana y Varela, 1992) que culmina con la autoconsciencia, entendida como "factor que permite la sustitución de la evolución biológica sometida a leyes de la selección natural por la evolución cultural dirigida y orientada por el yo consciente. Lo que nos hace más humanos es el hecho de poder hacernos autoconscientes, reflexionar sobre nuestros sentimientos y describirlos, tomar decisiones y modificar profundamente nuestra conducta emocional" 
(Álvarez Munárriz, 2015: 83). Se hace por tanto necesaria la consideración de la persona como una unidad bio-socio-cultural y el sufrimiento está presente en los tres ámbitos.

Las sociedades complejas en las que vivimos son el resultado de la asunción sin reservas de los paradigmas racionalista y positivista. A partir del primero reducimos las emociones, lo que conlleva una reducción de la complejidad de lo humano, y con menos factores que analizar, resulta mucho más fácil objetivar y cuantificar, aunque eso suponga deshumanizar. Como dice María Jesús Buxó "lo cierto es que progresivamente las emociones, los sentimientos, la sensualidad o las sensaciones corporales y las ideas razonables o irrazonables se han ido separando" (2003: 28). El sufrimiento no se reduce al dolor físico o el malestar, sino que debemos analizarlo como una de las realidades más conflictivas de la experiencia humana, ya que dificulta la búsqueda natural de placer y felicidad. Según la definición de dolor propuesta por la Asociación Internacional para el Estudio del Dolor (IASP), éste consiste en una sensación desagradable y una experiencia emocional, asociadas con una lesión tisular, actual o potencial o descrita en términos de dicha lesión. Si bien el dolor tiene un origen físico, el sufrimiento atraviesa toda la estructura antropológica del ser humano, tanto la psicofísica, como la psicoespiritual. Es el cuerpo el que experimenta dolor, pero es la persona la que lo sufre. Llegados a este punto, y situándonos en la antropología Biocultural, podríamos distinguir entre el sufrimiento físico que tiene una base biológica en el dolor de la enfermedad física o mental, y el sufrimiento social causado por la ausencia de sentido vital, no hay dolor, hay tristeza, incomprensión, desorientación, miedo, inestabilidad, inseguridad, infelicidad, culpabilidad, soledad, etc.

Aunque asumamos que el sufrimiento es una condición inherente a nuestra propia naturaleza, la globalización económica coloniza no solo culturas sino, y sobre todo, los cuerpos y las mentes de las personas, produciendo individuos enfermos cuyo sufrimiento será atribuido a un proceso de deterioro biológico. Cuando el cuerpo sufre, recurrimos al médico que consuela y mitiga el sufrimiento pero que recurre a la biologización como modo de silenciar el contexto y de esta forma no subvertir el orden establecido, en torno al cual gira el sistema capitalista. Le Breton (2000) en Antropología del Dolor, afirma: "sufrir, es sentir la propia condición personal en estado puro sin poder movilizar otras defensas que las técnicas o las morales [...]". En la misma obra, el autor insta a la medicina a la supresión de la biologización del dolor-sufrimiento, sustituyendo la misma por la humanización y la contextualización. Para saber qué causa el sufrimiento hay que preguntarle a quien lo sufre y esa es la forma más completa, integral y personalizada de establecer la relación médico paciente. En la misma línea, el doctor Molina López (2011: 8) reconoce que,

"los profesionales de la salud tenemos la obligación moral de ampliar nuestra óptica del paciente, descubriendo el sufrimiento y ubicando en lo posible su fuente, para emplear todos los medios proporcionados disponibles para aliviarlo, teniendo en cuenta para ello al hombre en su dimensión holística".

Pero también advierte que esta implicación de los profesionales de la salud produce un sufrimiento empático que es neutralizado por los estudiantes de Medicina que "desarrollan rápidamente destrezas tecnológicas para enfrentar virtualmente cualquier crisis que el paciente pueda presentar; pero para su propia supervivencia emocional, aprenden a ignorar o a minimizar las señales de sufrimiento personal de sus pacientes" (Molina López, 2011:7)He aquí, como dice Sanmartín (2010: 16) "dos de las manifestaciones del nuevo mal: insensibilidad al sufrimiento y deseo de colonizar la privacidad [...] un síntoma de insensibilidad y falta de sentido".

De la definición de ser humano como "animal simbólico" que formulan Cassirer y White podemos inferir que nuestra especie, que conozcamos, es la única capaz de transformar los signos en símbolos, más o menos complejos, y viceversa y que sólo la mente humana desig- 
na y otorga significado a la realidad (Tattersall, 2012). De ahí que la antropología, en tanto que disciplina que se afana en comprender su naturaleza también debe fijar su objeto de estudio en el hombre como productor de sentido (Lisón Tolosana, 1998). El sentido podría definirse como un concepto relacional a través del cual, los seres humanos otorgan significado a sus actos y al mundo que los rodea. La pregunta por el sentido de la vida que preocupa a las personas se puede analizar desde una triple perspectiva, la razón de ser, el significado y la dirección (Álvarez Munárriz, 2000: 159). El sentido como razón de ser se fundamentaría en la dificultad cognitiva que tiene la mente humana para asumir el caos, lo que implica que para el hombre la realidad adquiere sentido cuando la percibe estructurada de manera armónica y coherente. En tanto que significado, el individuo atribuye sentido a su vida cuando se siente satisfecho y orgulloso de ella, atribución que no se realiza de manera aislada sino en tanto que miembro de la sociedad. "No hay sentido sin intención, no hay sentido sin relación con la libertad, no hay sentido, por tanto, sin un sujeto que establece comunicación con otro sujeto" (Ferry, 1999: 314). Por último, el sentido como orientación nos permite reducir la complejidad y la incertidumbre selectivas (Luhman, 1998: 29) y nos ayuda a la selección entre posibilidades funcionalmente equivalentes y a la búsqueda de nuevas posibilidades (Antón Hurtado, 2012), aunque, como dice Bauman (2015), sin que se pueda resolver los dilemas que se plantean actualmente. En palabras de Sanmartín (2010: 15):

"vivimos en una realidad de posibilidades, no de dilemas [...] donde no existe la moralidad. Es obligatorio espiar y filtrar, aunque no está claro por qué razón y con qué fin. Es algo [...] tecnológicamente factible".

Conferir un sentido al sufrimiento físico puede constituir una forma de gestión, afrontamiento y manejo de la enfermedad. Para Rosario Otegui (2000:227:248) el discurso biomédico se fundamenta en la división cartesiana del ser humano con categorías que "dicotomizan y autonomizan el cuerpo y la mente", el cuerpo queda como una unidad independiente descontextualizada en el que se aplica un método científico que opera de forma objetiva; esta actitud basada en la concepción biológica/psicológica del ser humano oculta el carácter social del sufrimiento "... al construir un objeto que se articula en torno a la visualización del padecimiento de forma ahistórica y psicosomática la biomedicina abandona las explicaciones en términos de causalidades y construcciones socioculturales" (Otegui, 2000:239), ya que deja fuera la relación entre la vivencia de la enfermedad y las formas en que el individuo la interpreta y la afronta porque anula los recursos personales y culturales destinados a asistirnos en el propio sufrimiento. Esta autora refiere que para las personas que sufren, $e l$ dolor es la enfermedad, es el único elemento que permite designar el mal al constituirse en la sensación que hace visible y articula la experiencia del sufrimiento, ya que éste se entiende como un operador simbólico que adquiere su sentido a través del análisis de la construcción sociohistórica en la que se desarrolla. El dolor y el sufrimiento son consustanciales a la vida humana, incluso cuando gozamos de buena salud, las personas hemos demostrado una gran habilidad para crear nuestro propio sufrimiento; desde sus inicios la vida humana ha estado influida por el hecho de la finitud y de la mortalidad. Nuestros cuerpos están expuestos a enfermedades agudas y crónicas, a la fragilidad y al deterioro, al dolor y al sufrimiento y por si esto no fuere suficiente, llevamos el sufrimiento añadido de ver como enferman y mueren nuestros padres, familiares y amigos que con frecuencia es más difícil de soportar que las propias aflicciones.

El sufrimiento social no está causado exclusivamente por el dolor físico y su repercusión emocional, más bien se refiere a una expresión de la condición humana más extraordinaria, que es la base de la evolución cultural, y que consiste en que en los seres humanos, no hay acción sin intención, y esa intencionalidad se fundamenta en el conjunto de creencias, valores y normas que se forjan a través de la cultura, por tanto, el sufrimiento social se produce 
cuando hay un choque entre las creencias y los valores de la sociedad y la de las personas o la imposibilidad de aplicarlas. En este caso, es la tensión de la adaptación cultural la que induce la aparición de enfermedades, tanto físicas (enfermedades laborales), como psicológicas (depresión, estrés, ansiedad, etc.) tan frecuentes en las sociedades complejas y que responden a la carencia de sentido, como señala Spaemann (1993) "el sufrimiento aparece allí donde no se acierta a integrar una situación dentro de un contexto de sentido". Que las sociedades complejas sean cada vez más edonistas y que sus habitantes intenten evitar el dolor a toda costa, nos incapacita para padecerlo y como dice Roqué (2006: 129) nos deja "sin recursos para hacerle frente, se convierte en fuente de frustraciones existenciales y aumenta con ello el sufrimiento ".

Comparto con Fassin (2004) la conveniencia de situar el sufrimiento social en un contexto global de embrutecimiento del mundo basado en la violencia política y colectiva que se ejerce sobre la población mundial a través de modelos económicos, políticos y de organización social, que han provocado, lo que David Harvey (2011) llama un "ajuste espacio-temporal". La modificación del "complejo cronotopo" ha supuesto el despliegue de una serie de cambios profundos y generalizados que se suceden de manera trepidante y que requieren respuestas rápidas, irreflexivas, insatisfactorias y atomizadas, de manera que,

"nadie es realmente capaz de conectar todos los puntos y ver la imagen entera [...] y nadie tiene ninguna pista de hacia dónde nos dirigimos con tanta precipitación. Puesto que ya nadie entiende el sistema, nadie puede detenerlo" (Harari, 2016: 64).

Hemos pasado de ser reflexivos y analíticos en nuestra toma de decisiones a decidir "sobre la marcha" o ir con "el piloto automático" en clara alusión a una suerte de comportamiento determinístico e involutivo respecto a lo que hasta ahora nos diferenciaba del resto de las especies. Aunque nuestros días siguen teniendo veinticuatro horas, hemos ampliado considerablemente la actividad que desplegamos a lo largo de las mismas, porque con las nuevas tecnologías de la comunicación, el mundo virtual se ha infiltrado en nuestras vidas embruteciendo nuestro comportamiento, desde la forma de expresarnos hasta la ruptura con las normas más básicas de educación. En efecto, la revolución científica y tecnológica y la secularización han contribuido a la pérdida de sentido. Como decía Durkheim en Las formas elementales de la vida religiosa,

"la fe es sobre todo un estímulo para la acción, mientras que la ciencia, aunque se la lleve hasta sus últimas consecuencias, siempre se mantiene alejada de ella. La ciencia es fragmentaria e incompleta; avanza, aunque lentamente y nunca tiene fin; pero la vida no puede esperar. Por eso las teorías destinadas a hacer vivir y actuar a los hombres se ven obligadas a dejar atrás a la ciencia y a completarla prematuramente" (Horton, 1980: 40).

La concepción del sufrimiento depende en gran medida de la cosmovisión del mundo y de la interpretación de la realidad objetiva que cada persona le dé a este fenómeno. En nuestro entorno cultural de tradición cristiana, para la Iglesia la enfermedad y el sufrimiento siempre tiene un significado "(...) ofrecer junto con Cristo vuestra condición de sufrimiento al Padre" (Benedicto XVI, 2006). Por otro lado en la carta apostólica "Salvificidoloris" Juan Pablo II (1984) afirma como en el Antiguo Testamento se identifica el sufrimiento con el mal, y de este modo podemos constatar en el libro de Job cómo el sufrimiento se produce por la trasgresión del orden natural creado por Dios. Sufrimiento y desorden serían equivalentes. Concluye el Papa afirmando: 
"En Cristo se revela el misterio del hombre, y el misterio del hombre es en especial el sufrimiento. En Cristo se revela el enigma del dolor y de la muerte. Sólo en el amor se puede encontrar la redención santifica del dolor. Que el dolor de María y los santos nos ayuden a encontrar esta redención. Que el sufrimiento se convierta en fuente de fuerza para toda la humanidad."

El dolor y el sufrimiento adquieren un significado de perfeccionamiento a través de la religión católica, y así, un mundo sin pecado sería un mundo estéril y por ende no productivo en un sentido espiritual del término. La secularización de las sociedades complejas ha supuesto la traslación de la fe religiosa a la fe científico-técnica y la sumisión de lo emocional a lo racional, lo que deja sin explicación al sufrimiento, pero no nos libera de su padecimiento, abocándonos a la mas cruel de las situaciones, que es la negación de lo sentido.

\section{Sufrimiento a lo largo del ciclo vital}

La vida se manifiesta a través del sufrimiento. La primera expresión de vida es el llanto del recién nacido y la ausencia de la misma, la recoge la sabiduría popular a través del dicho "ya no sufre, ni padece", esto es, no siente. Sentir es, con frecuencia, sufrir, y tanto las sensaciones como los sentimientos son causa de sufrimiento. La cultura poda la naturaleza, y aunque su desarrollo fue decisivo para nuestro éxito evolutivo, en el momento actual infringe a los individuos sufrimiento desde su nacimiento. A pesar de los consejos que la OMS ofrece sobre las bondades de la lactancia materna a demanda, de la carta de los Derechos del Niño, de las leyes de protección del menor, lo cierto es que los niños y niñas están sometidos a "adaptaciones culturales" que les causan sufrimiento y malestar. El paradigma racionalista bajo el que se asume su formación, destaca unas capacidades intelectuales en detrimento de otras capacidades o destrezas, que les podrían resultar más gratificantes.

Las niñas y los niños de las sociedades complejas están siendo sometidos a una reducción de la sociabilidad por el descenso de la natalidad, lo que supone el aumento de hijos únicos, y a la reducción del juego con sus iguales para poder desplegar una serie de destrezas que configuran su identidad y su pertenencia al grupo. Cada vez tenemos una infancia más aislada en la que se reduce la expresividad emotiva y relacional debido al uso de dispositivos informáticos que los insensibilizan, y más sometidos a la valoración de estándares de calidad basados en la competitividad y el individualismo que inducen un aumento del estrés y la ansiedad infantil (Siegel y PayneBryson, 2012). Como canta Vástago en su Cuento de Navidad:

\section{Hace tiempo atrás, la risa y la diversión, Un hechizo del más allá lo silenció. Los niños de la región, perdieron su imaginación Su infancia se marchitó y crecieron veloz}

Numerosos informantes me aconsejaban que disfrutara de la infancia de mi hija, porque "los niños crecen muy rápidos", pero esta percepción no responde a que crezcan más rápido que en otras épocas, sino a que, en esta sociedad acelerada, tenemos menos tiempo para acompañarlos y disfrutar de su infancia. Se suceden las celebraciones de los cumpleaños, pero se dificulta la concreción de momentos de disfrute compartido en cada uno de ellos. Por otro lado, esta sociedad paradójica, convierte a los niños en adultos, a través de la indumentaria, propiciando, de manera inconsciente, que numerosas mentes perturbadas se conviertan en pederastas o depredadores sexuales al amparo del anonimato de las nuevas tecnologías. Paralelamente a esta situación, y ahí radica la paradoja, los adultos se infantilizan con la vestimenta y el "complejo de Peter Pan” se hace más evidente. 
La ruptura de las expectativas para los jóvenes, es, si cabe, más dramática, porque se les induce a tomar decisiones importantes, que conllevan renuncia y sacrificio, en la mayoría de las ocasiones, pero no se les garantiza una compensación y la posibilidad de conseguir una vida plena y satisfactoria. En el marcado laboral actual, muchos de los que consiguen un trabajo, lo hacen a cambio de entregar gran parte de su tiempo. Me decía uno de mis estudiantes de cuarto curso de Criminología, que "cada día somos más alemanes, hemos pasado de trabajar para vivir a vivir para trabajar". La situación es todavía más insatisfactoria, cuando no tienen trabajo, porque entonces no pueden madurar vitalmente y se sienten una carga para sus familias. La frustración generada en estos casos les induce a buscar en el mundo virtual, lo que no pueden conseguir en el real, de manera que "queman su tiempo" entreteniéndose en algo totalmente ficticio y aislándose de las dinámicas familiares.

Cristophe Dejours, uno de los autores que más ha investigado sobre la tríada dolor-sufrimiento-trabajo, considera que no solo el trabajo, sino especialmente la organización y la gestión del trabajo, suponen la creación de sufrimiento, sobre todo cuando el autor analiza la experiencia neoliberal, a la que compara con los tiempos del nazismo. Alain Ehrenberg (1995) en su obra L'individu incertain, inscrita en el proyecto de "Una antropología de las sociedades democráticas", mantiene que la subjetividad se ha convertido en una cuestión colectiva a través de la creación de normas que vinculan la privacidad del individuo con las posibilidades del mismo: maneras de trabajar, formas de vivir en pareja, consejos para conservar la buena salud... Lo que provocará la saturación y paradójicamente la depresión y lo que Ehrenberg denomina la fatiga de ser uno mismo. Este ambiente depresivo, no es consecuencia del estrés provocado por la aparente posibilidad de elección y mejora de la calidad de vida, sino por la exigencia de poner a disposición del sistema productivo aspectos creativos, cognitivos y afectivos de las personas (Martín Consuegra, 2016).

Las expectativas han sido el vector guía que, gestionado por la cultura a la que se pertenece, orientaban el transitar vital de las personas. La gente mantenía la esperanza plausible en la consecución de sus objetivos, pero esa situación se ha difuminado en la actualidad, que nos enfrenta a un espejismo de felicidad, aumenta las posibilidades, pero reduce su implementación, sumiendo al individuo en escenarios de frustración que le hacen sufrir. La incertidumbre y la inestabilidad generada por el sistema económico neoliberal ha supuesto la quiebra de las expectativas a nivel individual y colectivo, y como dice Cassell (2013) genera un sufrimiento social al ser conscientes de la propia condición del tiempo y del futuro. Hasta la crisis de 2007, las generaciones habían mejorado las condiciones de vida de las anteriores, pero esa tendencia se quiebra para los jóvenes y los niños del siglo XXI. Los adultos viven con dolor la incertidumbre que el futuro les depara a sus hijos e hijas, cuando los tienen, y se culpabilizan, y también, hay una gran mayoría, que se culpabiliza por no tenerlos (especialmente las mujeres), asumiendo, en ambos casos, como responsabilidad propia lo que es una imposición del sistema, que como dice Harari (2016): "nadie tiene ninguna pista de hacia dónde nos dirigimos con tanta precipitación. Puesto que nadie entiende el sistema, nadie puede detenerlo". Aunque, "el sentimiento de culpabilidad engendrado por la cultura no se percibe como tal, sino que permanece inconsciente en gran parte o se expresa como un malestar, un descontento que se trata de atribuir a otras motivaciones" (Freud, 1930: 77). De esta manera, nos sentimos culpables de no disfrutar de nuestras niñas y niños, de no saber orientar a nuestros jóvenes y de no poder cuidar de nuestros mayores. El sistema neoliberal nos ha atrapado como "redoma entre dos piedras", situándonos entre las responsabilidad tradicional del cuidado de los otros y las exigencias de un sistema austericida que te abandona a tus posibilidades y recursos, haciendo inviable la dispensación de los mismos.

El cambio del modelo cultural de referencia tiene una repercusión especial en los ancianos, que habiendo generado unas expectativas de futuro basadas en su experiencia vital, se ven frustradas en el momento actual y les infringe un gran sufrimiento. Muchos ancianos esperaban ser cuidados como ellos habían cuidado de sus padres y habían visto cuidar a 
estos de sus abuelos, pero esa aspiración basada en la experiencia se ha truncado. En la huerta de Murcia, cuando se felicitaba a un padre por el nacimiento de una hija, se le decía "ya tienes quien te de sopas", lo que refería a una garantía de cuidados en la vejez, que se ha visto frustrada con las condiciones sociolaborales actuales. El aumento en la esperanza de vida, que fue una conquista civilizatoria, no resulta rentable para el sistema neoliberal, y con la quiebra del estado del bienestar, el cuidado de los ancianos dependientes supone unos costes económicos y temporales que muchas familias no pueden asumir, lo que supone para los ancianos un gran sufrimiento que les hace considerarse una carga para sus familiares. Este sentimiento también es compartido por los enfermos graves o crónicos desahuciados, porque el sufrimiento comienza no solo cuando la persona no es capaz de hacer algo, sino cuando es consciente de lo que le depara el futuro, lo que ha supuesto la reactivación del debate sobre la eutanasia, porque en una sociedad, cada vez más laica, la muerte no es lo peor. Hay estados de vida peores que la muerte misma, en los cuales ésta viene a presentarse como una salida, un alivio a un sufrimiento insoportable, un fin anhelado. Una informante de 90 años, me decía que ella rezaba todas las noches a San José patrón de la Buena Muerte para que le diera una "muerte ligera, que no padeciera, ni hiciera padecer". Resulta antropológicamente relevante, que no se pide por la salvación del alma, si no para evitar el sufrimiento personal y familiar que supone una larga agonía.

La convivencia en el entorno familiar sustenta el apego y la estabilidad emocional de sus miembros, pero los cambios y los ritmos de las familias del siglo XXI fomentan en "aislamiento familiar" es decir, que se vive bajo el mismo techo, pero no se convive en sentido estricto. La convivencia se ha fragmentado (Jung, 1981), la movilidad supone una separación de facto del núcleo familiar, lo que causa un sufrimiento mental en las familias, no sólo por el desarraigo, sino también por el desapego y el alejamiento de las dinámicas cotidianas, lo que provoca situaciones de estrés al interior del núcleo familiar.

\section{Conclusión}

La crisis del siglo XXI ha infringido un gran sufrimiento a buena parte de la población mundial. La cultura, que nos había dotado de toda una serie de estrategias de supervivencia y de sentido, que supusieron el éxito de nuestra especie, se está evaporando ante la primacía de unos intereses económicos gestionados por los poderosos y que obliga a la mayoría a adoptar una situación de "sobrevivencia", que refiere a sobrevivir, pero sin estrategias definidas, en entornos inestables, inciertos y carentes de sentido. En este contexto, el sufrimiento social se hace insoportable para, cada vez mayor número de personas que se quitan la vida, como demuestra el aumento de la tasa de suicidios, que suponen la primera causa de muerte en España y, desde el punto de vista antropológico, refiere a la quiebra del sentido que padecen los individuos.

\section{Bibiografía}

Álvarez Munárriz, L. (1997) “Empatía y simpatía” en Moreno, M. (Dir.) Diccionario de pensamiento contemporáneo. San Pablo, Madrid, 395-402.

Álvarez Munárriz, L.(2000) "El “sentido" como categoría de interpretación”, en Lisón Tolosana, C. (ed.). Antropología: Horizontes Interpretativos. Granada: Comares.

Álvarez Munárriz, L. (2011) "La compleja identidad personal” en Revista de Dialectología y Tradiciones Populares, vol. LXVI, n. 2.

Álvarez Munárriz, L. (2015) Categorías clave de la Antropología. Signatura Demos. Sevilla.

Antón Hurtado, F. (2012) “Antropología del Sinsentido”. En: Revista de Antropología Experimental, $\mathrm{N}^{\mathrm{o}}$ 12, Texto 27: 349-371 http://www.ujaen.es/huesped/rae/articulos2012/27anton12.pdf 
Antón Hurtado, F.; Ercolani, G.(2013) "Introduction: Anthropology and Security Studies" en Anthropology and Security Studies, Universidad de Murcia; Nottingham Trent University; College of William and Mary (USA), 2013, 25-55 http://www.diegomarin.net/umu/en/ sociologia-y-antropologia/1133-anthropology-and-security-studies $9788416038008 . \mathrm{html}$

Antón Hurtado, F.; Martín-Consuegra Martín-Fonseca, M.D. (2013). "El papel silenciador de la biomedicina en la victimización por el trabajo". En: Revista Nuevas Tendencias en Antropología. $N^{o} 4$, 2013, 153-172. Disponible en: http://www.revistadeantropologia.es/Textos/ $\mathrm{N} 4 / \mathrm{El} \% 20$ papel\%20silenciador\%20de\%labiomedicina.pdf

Antón Hurtado, F.. (2015a) "Antropología del miedo". En: methaodos. Revista de ciencias sociales. Vol.3, Num.2, 262-275 http://www.methaodos.org/revistamethaodos/index.php/methaodos/article/view/90

Antón Hurtado, F. y Ercolani, G. (2015b) "Antropología de la seguridad: de la estructura al sentimiento”. En: Cultura y conciencia. Revista de Antropología 2015, n. 1 http://culturayconciencia.es/

Bauman, Z. (2015) Ceguera moral: la pérdida de sensibilidad en la modernidad líquida. Paidós. Barcelona.

Benedicto XVI (2006) XIV Jornada Mundial del Enfermo. (11 de febrero de 2006)

Buxó i Rey, M ${ }^{\mathrm{a}}$ J. (2003)“Delicadeza y extravagancia en las pasiones: paisajes de la emoción en las fronteras culturales de Nuevo México" en Lisón Tolosana, C. (Ed.)Antropología: horizontes emotivos. Granada. Universidad de Granada, 27-55.

Cassell, E. (2013)The Nature of Healing. Oxford. Oxford UniversityPress.

Darwin, C. (1998 [1872]) La expresión de las emociones en los animales y en el hombre. Madrid, Alianza.

De Pina Cabral, J. (2003) "La ficción como exutorio" en Lisón Tolosana, C. (Ed.) Antropología: horizontes emotivos. Granada. Universidad de Granada, 97-105.

Damasio, A. (2011): Self comes to mind. Constructing the conscious brain. London: Vintage Books.

Dejours, C. (2009). Trabajo y sufrimiento: cuando la injusticia se hace banal. Madrid. Ed. Modus Laborandi.

Ehrenberg, A. (1995)L'Individu incertain. París. Hachette.

Ehrenberg, A. (2000) La fatiga de ser uno mismo. Depresión y sociedad. Buenos Aires. Edt. Nueva Visión.

Fassin D. (2004), Et la souffrance devient sociale. De l'anthropologie médicale à une anthropologie des afflictions, Critique, Tome LX-nº 680-681, 16-29.

Fericgla, J.M ${ }^{\mathrm{a}}$ (2012) “Cultura y emociones. Manifiesto por una Antropología de las emociones” en http://web.usal.es/ meilan/LA\%20RISA\%20CD/mundorisa/risauniversal/Antropologia. htm

Ferry, L.(1999) “¿La búsqueda de sentido es una ilusión?” En Comte-Spanville, A. y Ferry, L, La sabiduría de los modernos. Barcelona: Península.

Freud, S. (1972 [1915]) "Lo inconsciente" en Obras completas, vol. VI. Madrid. Biblioteca Nueva.

Freud, S. (1972 [1915]) “Compendio del psiconálisis" en Obras completas, vol. IX. Madrid. Biblioteca Nueva.

Freud, S. (1982 [1930]) El malestar en la cultura. Madrid. Alianza.

Harari, Y.N. (2016) Homo Deus. Breve historia del mañana. Barcelona. Debate.

Horton, R. (1980) Lévy-Bruhl, Durkheim y la revolución científica. Barcelona. Anagrama.

Ingold, T.(1991) "Becoming Persons: Conciousness and Sociality in Human Evolution" en Cultural Dynamics. $\mathrm{N}^{\circ} 4,355-378$

Juan Pablo II, (1984) Carta apostólica “Salvificidoloris” a los obispos, sacerdotes, familias religiosas y fieles de la Iglesia Católica sobre el sentido cristiano del sufrimiento humano.

Jung, C.G. (1981 [1961]) Recuerdos, sueños, pensamientos. Seix Barral, Barcelona.

Kandel, E. R. (2013) La era del inconsciente. Barcelona. Paidós

Kellerman. (2013). El empleado doblemente libre: El individuo extenuado después de su hundimiento. Constelaciones: Revista de Teoría Crítica. $\mathrm{N}^{\mathrm{o}} 5$

Le Breton, D. (1999), Las pasiones ordinarias. Antropología de las emociones, Buenos Aires, Nueva Visión. 
Le Breton, D. (2000), Antropología del dolor, Barcelona, Seix Barral

Levinas, E. (1993 [1987]) Entre nosotros. Ensayos para pensar en otro. Valencia. Pretextos.

Lisón Tolosana, C. (1998) "Antropología” en Lisón Tolosana, C. (Ed.) Antropología: Horizontes Teóricos. Granada, Comares.

Lisón Tolosana, C. (2003) Antropología: horizontes emotivos. Granada. Universidad de Granada.

Lisón Tolosana, C. (2005). "La otra vía (Ciencia y razón antropológica)". Anales de la Real Academia de Ciencias Morales y Políticas (82), 161-186.

Luhman, N.(1998) Complejidad y modernidad, De la unidad a la diferencia. Madrid: Trotta.

Maffesoli, M. (1997), Elogio de la razón sensible. Una visión intuitiva del mundo contemporáneo, Barcelona, Paidós,

Mairal Buil, G. (2003) "Discursos de riesgo y agonía” en Lisón Tolosana, C. (Ed.)Antropología: horizontes emotivos. Granada. Universidad de Granada, 131-141.

Martín Consuegra Martín Fontecha, MD. (2016). Tesis doctoral titulada Estudio antropológico de la biomedicina en el sufrimiento laboral (Universidad de Murcia)

Maturana, H.R., y Varela, F.J. (1980) Autopoiesis and cognition: the recognition of the living. Dordrecht, Reidel.

Mauss, M. (1991 [1968]) Sociología y Antropología. Madrid, Tecnos

Mead, G.H. 2008 [1931] Filosofía del presente. Madrid. CIS

Milton, K. (2005): "Emotion (or life, the universe, everything)" The Australian Journal of Anthropology, $16 / 2$.

Molina López, J.A., (2011) "El sufrimiento humano como experiencia personal y profesional" en Rev. Bioética, No 6 (Mayo-Agosto), 4-9

Otegui Pascual, R. (2000). Factores socioculturales del dolor y el sufrimiento. En

Perdiguero, E. y Comelles, J.M. (Ed.), Medicina y cultura. Estudios entre la Antropología y la medicina. Barcelona: Bellaterra, 227-248

Pérez Álvarez, M. (2012). La Psicología política. Magina Simpática. Papeles de Psicología, Vol 33, 183-201

Ramírez Goicoechea, E. (2001) “Antropología “compleja” de las emociones humanas” en Isegoría, $\mathrm{n}^{\circ} 25,177-200$

Roqué, MV. (2006). "El significado del dolor en la existencia humana”. En: García Marqués, A.; Guerrero Muñoz, J. (eds.). Cultura juvenil y sentido de la vida. Isabor. Murcia, 127-146.

Sanmartín Arce, R. (2010): Imágenes de la libertad y figuración antropológica en el horizonte de nuestra época. Madrid. Real Academia de Ciencias Morales y Políticas.

Siegel, D. J. y Bryson, T. (2012): El cerebro del niño, Barcelona, Alba.

Spaemann, R. (1993) “El sentido del sufrimiento" En: Aciprensa. (recurso electrónico). Disponible en: http://www.aciprensa.com/Familia/sufrimiento.htm

Tattersall, I. (2012) Los Señores de la Tierra: la búsqueda de nuestros orígenes humanos, Barcelona, Edt. Pasado Presente.

\section{3}

